\title{
COPIM
}

\section{Open access publishing and the promise of collaboration}

\author{
Joe Deville
}

Published on: May 04, 2021

DOI: 10.21428/785a6451.5ba5502c

License: Creative Commons Attribution 4.0 International License (CC-BY 4.0). 
As a researcher in the contemporary academy, I have become used to being expected to collaborate. In many ways this is to be welcomed, given that a focus on collaboration helps decentre a model of academia dominated by the figure of the individual genius, doggedly ploughing his [sic] lonely but serious scholarly furrow. Indeed, I am involved in a number of projects and initiatives that to my mind showcase some of the very best possibilities of academic collaboration, by challenging departmental silos, or by working across disciplines to develop new methods or to solve complex research questions. One of these is the COPIM project, on whose ongoing work this blog post reports, which aims to build 'a significantly enriched, not-for-profit and open source ecosystem for open access book publishing'.

However, it also needs to be recognised that in some contexts, collaboration is increasingly being seen as a means towards marketized academic ends in ways that many of us would see as in tension with the pursuit of open, creative, critically attuned research. In the UK, the Knowledge Exchange Framework (KEF), the latest powerful actor in the ever-deepening metricisation of scholarly work, is emblematic of this. The first results have just been published and the new pie chart forward KEF dashboard reveals that Lancaster University, where I am based, is apparently 'good' at collaboration: it is in the **TOP $20 \%$ !!** for both 'Working with business' and 'Working with the public and third sector' (what I probably shouldn't draw attention to, is that it is in the (bottom 30\%) for 'Skills, enterprise and entrepreneurship'). At present, such results are not directly tied to the allocation of government funding, as is the case with its much-maligned cousin the Research Excellence Framework (REF). Instead, the results are intended 'to provide institutions with information about their own performance in knowledge exchange in order to facilitate improvement'. I can only presume that the questionable privilege of being allowed to self-discipline rather than being made a subject of direct discipline by the state will prove temporary.

In the discussions about the merits and demerits of collaboration, what tends to be missed though are the untapped potentials that exist in collaborations not just between academics, or between disciplines, or between academics and external organisations, or between academics and the public, but between academics, scholarly libraries, and publishers of scholarly work. This the subject of a new report co-authored by Elli Gerakopoulou, Izabella Penier and me. It focuses on the possibilities that might exist for collaboration between scholarly libraries and open access book publishers, including the kinds of open access publishers led by academics represented by ScholarLed, one of the partners in the COPIM project and with which I am also 
involved. The report draws on a combination of interviews, workshop discussions (including one workshop with librarians in the US, one in the UK, and one with publishers), and pre-workshop surveys with librarians and individuals involved in library consortia, as well as desk research.

In the report we examine various forms of collaboration that characterise the existing landscape of open access book publishing. This includes examining library membership programmes, of the kind run by both publishers - examples include programmes run by Lever Press, Luminos, punctum books, and $\underline{\text { Open Book }}$ Publishers - and infrastructure providers notably the OAPEN library membership programme. We also look at intermediaries that aim to increase the likelihood of open access book publishers being able to receive financial support from scholarly libraries, such as Knowledge Unlatched and TOME. This forms part of a scoping exercise to enable us and our readers to understand the diversity of types of collaboration that already exist between and around open access publishers and scholarly COPIM The promise of collaboration: collective funding models and the integration of OA books into libraries

Elli Gerakopoulou, Izabella Penier, Joe Deville DOI: 10.528//zenodo.4756894

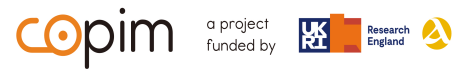

https://doi.org/10.5281/zenodo.4 $\underline{756894}$

libraries and where there are possibilities to learn from such initiatives.

The report also explores how such existing programmes, as well as hypothetical programmes introduced to workshop participants, are seen from the perspectives of libraries and higher education institutions themselves. The stories that our library colleagues repeatedly recounted to us, in both the UK and the US, were often characterised by constraints. Most obviously, this includes financial constraint: the impact of the Covid-19 pandemic on budgets has squeezed, or at the very least is anticipated to squeeze, an already limited capacity to support open access projects through direct forms of financial support. We heard about technicial constraints, such as the difficulty of making open access content as discoverable as it should be in library catalogues. We were also told about communicative constraints: how hard those working in scholarly libraries often find it to articulate the value of open access to their colleagues, whether that be academics or those working in managerial role, 
with the latter often acting as gatekeepers to institutional funding for open access. In this respect, many library colleagues found themselves sometimes frustrated by the inability of open access initiatives to communicate not just why supporting open access mattered for the scholarly landscape as a whole, but also for them: for their students, for their researchers, for their institutional priorities.

This might seem rather a bleak context to report on as part of a project looking to explore ways of securing a more sustainable future for open access book publishing. However, there is at least something in the usually trite observation that in challenges lie opportunities. The increasing recognition by varied actors of the urgent need to build up capacity in open access publishing - including recognition by funders, of which the COPIM project was a beneficiary - provides a rare opportunity to address some of these challenges head on. How precisely can we work with colleagues to enable open access books to be better integrated into library catalogues? How can those looking to advocate for open access be provided with better evidence of, and better arguments for, the value of supporting open access publishing? And, as part of this, how can it be made easier to articulate both the global and local benefits of supporting open access?

These questions should not be understood as merely rhetorical. I and my colleagues in the 'Revenue Management and Infastructures' work package of the COPIM project are in the process of designing a platform that aims to address such issues directly. In the report we outline the objectives and key principles of the platform, an iteration of principles that have been previously outlined. In other parts of the COPIM project we are also exploring how collaborative library membership programmes might help closed access university presses convert their output to at least partially open access models via the Opening the Future platform.

However, no platform can hope to solve the challenge of open access publishing alone. While developing new and genuninely open infrastructures is vital for the future flourishing and ongoing reconfiguration of open access publishing, such infrastructures depend on parallel reconfigurations in the academy. It is the strong belief of me and my COPIM colleagues that new collaborations, new partnerships, new collectives, involving librarians, scholars, open access infrastructure providers, and open access content producers, are essential to this endeavour. This is, then, an argument for collaboration not as an instrumental, marketised end, but as a vector for creative, critical, and community-spirited efforts to open up the circulation of academic knowledge. 
Header image by Stephen Downes, used under a CC BY-NC 2.0 license. 